\title{
Educação Integral, Híbrida e Inclusiva na perspectiva Construcionista, Contextualizada e Significativa (CCS)
}

\author{
Klaus Schlünzen Junior ${ }^{1}$ \\ Elisa Tomoe Moriya Schlünzen ${ }^{2}$ \\ Jeong Cir Deborah Zaduski ${ }^{3}$ \\ Sandra Giovina Ponzio ${ }^{4}$ \\ Maria Claudia Leme Lopes da Silva ${ }^{5}$
}

Recibido: 05-06-2019

Aceptado: 10-09-2019

\section{Resumo}

Nas demandas do século 21, a escola ultrapassa a dimensão do desempenho acadêmico proveniente da acumulação de conteúdos, na direção de um conhecimento mobilizador que exige uma posição protagonista do estudante, isto é, uma possibilidade de saber e fazer. Essa configuração requer um currículo referenciado em

1. Professor Associado da Universidade Estadual Paulista - Unesp

Doutor em Engenharia Elétrica e Livre-docente em Informática e Educação

ORCID: https://orcid.org/0000-0002-5623-6093

Google Acadêmico: https://scholar.google.com.br/citations?user=4UlnQgOAAAAJ\&hl=pt-BR

Correo electrónico: klaus.junior@unesp.br

2. Professora Associada da Universidade Estadual Paulista - Unesp e da Universidade do Oeste Paulista - Unoeste

Doutora em Educação e Livre-docente em Formação de Professores para uma Escola Inclusiva ORCID: https://orcid.org/0000-0003-1138-8541

Google Acadêmico: https://scholar.google.com.br/citations?user=XIMkGQUAAAAJ\&hl=pt-BR Correo electrónico: elisa.tomoe@unesp.br

3. Pesquisadora do Centro de Promoção para a Inclusão Digital, Escolar e Social e doutoranda do Programa de Pós-Graduação em Educação da Unesp ORCID: https://orcid.org/0000-0001-8191-6683

Google Acadêmico: https://scholar.google.com.br/citations?user=510_ IkUAAAAJ\&hl=pt-BR

Correo electrónico: deborah_zaduski@hotmail.com

4. Gerente de Projetos do Instituto Ayrton Senna

ORCID: https://orcid.org/0000-0001-9689-8406

5. Gerente de Projetos do Instituto Ayrton Senna

ORCID: https://orcid.org/0000-0001-8555-6072 
competências e, todavia, as competências cognitivas, por si só, não são suficientes para formar esse estudante capaz de enfrentar os desafios do século 21, daí a emergência de uma Educação Integral que vise o desenvolvimento pleno, por meio de competências cognitivas e socioemocionais. O reconhecimento dos prejuízos da fragmentação do conhecimento e da supervalorização da dimensão racional revelou, no campo educacional, a necessidade de ações de integração curricular e de abordagens que promovam o desenvolvimento pleno - cognitivo e socioemocional, mediado pelo uso das tecnologias digitais. A formação de professores com estas competências na perspectiva Construcionista, Contextualizada e Significativa (CCS) é o foco deste artigo, que une a expertise do Instituto Ayrton Senna (IAS) na formação integral com a da equipe da Universidade Estadual Paulista (Unesp), que desenvolve pesquisa relacionadas a formação segundo esta abordagem.

Palavras chave: educação integral, inclusão, educação híbrida, abordagem CCS.

\section{Educación integral, híbrida e inclusiva en la perspectiva Construccionista, Contextualizada y Significativa (CCS)}

\section{Resumen}

En las demandas del siglo 21, la escuela sobrepasa la dimensión del desempeño académico proveniente de la acumulación de contenidos, en la dirección de un conocimiento movilizador que exige una posición protagonista del estudiante, es decir, una posibilidad de saber y hacer. Esta configuración requiere un currículo referenciado en competencias $y$, sin embargo, las competencias cognitivas, por sí solas, no son suficientes para formar a ese estudiante capaz de enfrentar los desafíos del siglo XXI, de ahí la emergencia de una Educación Integral que apunta al desarrollo 
pleno, por medio de competencias cognitivas y socioemocionales. El reconocimiento de los perjuicios de la fragmentación del conocimiento y de la sobrevaloración de la dimensión racional, puso de manifiesto, en el campo educativo, la necesidad de acciones de integración curricular y de enfoques que promuevan el pleno desarrollo cognitivo y socioemocional, mediado por el uso de las tecnologías digitales. La formación de maestros con estas competencias en la perspectiva Construccionista, Contextualizada y Significativa (CCS) es el foco de este artículo, que une la experiencia del Instituto Ayrton Senna (IAS) en la formación integral con la del equipo de la Universidade Estadual Paulista (Unesp), que desarrolla investigaciones relacionadas con la formación según este enfoque.

Palabras clave: formación integral, educación inclusiva, educación hibrida, enfoque constructivista contextualizada y significativa.

\title{
Comprehensive, hybrid and inclusive education in the Constructionist, Contextualized and Significant perspective (CCS)
}

\begin{abstract}
In the 21st century demands, school overcomes the dimension of academic performance coming from the accumulation of contents, towards a mobilizing knowledge that demands a protagonist position of the student, i.e., a possibility to know and do. This configuration requires a curriculum referenced at competencies, and yet, the cognitive skills alone are not sufficient to form this student capable of facing the challenges of the 21 st century, hence the emergence of an Integral Education aimed at the complete student development, based on cognitive and socialemotional competencies. The acknowledgment of the damages
\end{abstract}


of knowledge fragmentation and of the rational dimension overvaluation has revealed, in the educational field, the need for curricular integration actions and, of approaches that promote the full student development - cognitive and socio-emotional, mediated by the use of digital technologies. The teacher training with these competencies in a Constructionist, Contextualized and Significant approach (CCS) is the focus of this article, which unites the expertise of the Ayrton Senna Institute (IAS) in the integral training with the team of the Sao Paulo State University (Unesp), that develops researches related to training programs developed in accordance with this approach.

Keywords: integral education, inclusion, blended learning, CCS approach.

\section{Introdução}

Segundo dados do NMC Horizon Report: 2018 (Adam Becker et al, 2018; Quintana, 2019), e os avanços da 2019 (EDUCAUSE, 2019), entre os principais desafios presentes no uso de tecnologias nos contextos do Ensino Superior está a dificuldade em proporcionar experiências de aprendizagem que conectem a universidade com a vida, proporcionando experiências de aprendizagem autênticas e; as dificuldades em promover uma cidadania digital que possibilite aos aprendizes uma compreensão do ambiente digital, possibilitando que estes saibam como utilizar com propriedade e responsabilidade os recursos tecnológicos digitais para uma sociedade melhor, onde não apenas os aspectos cognitivos sejam considerados, mas uma formação que considere o desenvolvimento de competências socioemocionais.

Além disso, já em 2014, o mesmo relatório indicava as transformações no setor pelas quais passaremos nos próximos anos e 
que sinalizam problemas que precisam ser abordados. Destacamse entre eles: a integração entre aprendizagem online, colaborativa e híbrida; desenvolvimento de tecnologia educacional para o ensino superior, com metodologias ativas e modelos híbridos de educação; o uso das tecnologias de maneira intensa como meio de construção de ambientes de aprendizagem contextualizados e significativos.

Diante de um mundo cada vez mais conectado e tecnológico, não será possível conceber ambientes de aprendizagem sem explorar as potencialidades das tecnologias. Para tanto, as instituições de ensino superior precisam avançar na direção de repensar suas práticas, uma vez que as que mantém como eram no século passado, o que tornaram-se desinteressantes para os estudantes e não atendem a sociedade de modo geral, tendo em vista que não serão capazes de formar profissionais capazes de suprir às demandas do mundo de trabalho e educacional.

A implementação de modelos híbridos de educação (blended learning), estimula-se a mobilidade virtual e ao mesmo tempo favorece-se o processo de intercâmbio acadêmico, uma vez que as tecnologias permitem que estudantes de diferentes instituições compartilhem ambientes virtuais de aprendizagem, estabelecendo um rico ambiente de aprendizagem com contextos diversos, respeitando os aspectos culturais e permitindo a valorização das diferenças e a equidade.

A European Association for Quality Assurance in Higher Education, órgão da comunidade europeia recentemente publicou um importante estudo (Huertas et al, 2018) que aborda e apresenta diretrizes para a garantia da qualidade na educação superior. Isso indica que nos países desenvolvidos, a discussão se a educação a distância ou híbrida tem seu valor ou não, ou se funciona ou não, é totalmente superada. A preocupação principal reside na qualidade das ofertas de educação que são mediadas pelas tecnologias, destacando que o cenário que se apresenta nos leva na direção de uma combinação de presencialidade e virtualidade, na constituição de uma educação híbrida permea- 
da por critérios de qualidade que precisam estar muito bem definidos.

Diante disso, a qualidade se torna um dos condicionantes para a formação profissional daqueles que almejam fazer parte do mundo do trabalho, cada vez mais globalizado, articulado, criativo, inclusivo e dinâmico. As características que definem a qualidade almejada perpassam por diversos aspectos que devem subsidiar a construção e oferta de ações formativas por meio das tecnologias.

Em um cenário mundial, já se observam avanços com as preocupações de qualidade das ofertas de educação, que tomam lugar nos aspectos metodológicos, com abordagens de ensino e de aprendizagem que transformam o estudante no protagonista de sua aprendizagem; nos recursos e materiais didáticos empregados, com recursos de acessibilidade e tecnologia assistiva; em uma gestão mais participativa nas IES com ampla presença de todos os participantes nas decisões acadêmicas, administrativas e de regulação.

Diante deste cenário pretendemos com este artigo apresentar uma experiência exitosa de formação híbrida de professores em educação integral e inclusiva, por meio da abordagem Construcionista, Contextualizada e Significativa (CCS), cujos resultados trouxeram importantes contribuições para os estudantes e professores, principalmente relacionados aos aspectos da construção de ambientes de aprendizagem mais inclusivos e cujas competências socioemocionais foram desenvolvidas.

\section{Os Desafios da Educação para a Formação Integral no Século XXI}

Há tempos o conceito de Educação Integral tem ganhado destaque no Brasil, tanto em marcos legais, quanto em iniciativas educacionais. No histórico brasileiro, muitos projetos e políticas trataram o tema pelo viés da ampliação do tempo, com intencionalidades que 
variaram da esfera da assistência social (manter as crianças e jovens longe das ruas) à oferta de atividades lúdicas ou culturais que não se articulavam como um currículo. Ainda hoje, diversos projetos e políticas de educação integral são marcadamente voltados à ampliação da jornada escolar e, apesar de trazerem uma intenção valiosa de ampliar oportunidades de aprendizagem, correm o risco de fragmentar ainda mais os currículos e pouco contribuírem para a qualidade da formação dos estudantes.

O texto legal mais recente que traz para o debate o propósito da educação como desenvolvimento pleno é a Base Nacional Comum Curricular (BNCC) do Brasil (Ministério da Educação, 2018), documento federal que tem como objetivo normatizar os currículos estaduais e municipais, de modo a garantir uma base de princípios e de organização dos conhecimentos e competências comuns a todos eles. Nesse contexto, a BNCC afirma, de maneira explícita, "o seu compromisso com a educação integral, reconhecendo que a educação básica deve visar à formação e ao desenvolvimento humano global, o que implica romper com visões reducionistas que privilegiam a dimensão intelectual (cognitiva) ou a dimensão afetiva, ou, ainda, que confundem 'Educação Integral' com 'educação ou escola em tempo integral'.

Pesquisa realizada pela Fundação Getúlio Vargas (FGV) no Brasil constata que, embora cada setor possua necessidades específicas em termos de competência, o investimento no desenvolvimento de habilidades socioemocionais é importante para melhorar capital humano e a empregabilidade dos trabalhadores em todos os setores da sociedade. Ainda, as pesquisas de Durlak et al. (2011) e Sklad et al. (2012) trazem evidências que os programas com foco no desenvolvimento de competências melhora aprendizagem dos estudantes, e o resultado, segundo a pesquisa, é mais efetivo quando o programa é realizado na escola pelo professor da sala de aula.

Por sua vez, formar professores na perspectiva das salas de aula do século 21 requer um esforço na superação da distância entre conhecimento científico cultural e a realidade escolar e os problemas vividos pelos professores. Dado esse contexto, a parceria 
entre o Instituto Ayrton Senna e pesquisadores da Unesp propõe a realização de cursos de formação de professores que permitirão superar a dicotomia entre escola e academia, por meio de uma proposta que integra os diferentes saberes constituídos pelas duas instituições e que já foram testadas em diferentes contextos.

O curso foi desenvolvido na modalidade híbrida e em módulos, no Ambiente Virtual de Aprendizagem (AVA) Moodle, e trata da visão de Educação Integral e o desenvolvimento intencional de competências cognitivas e socioemocionais com foco no potencial e centralidade de crianças, adolescentes e jovens no processo educativo. Propõe também formas de viabilizar essa proposta em um projeto pedagógico para ser implantado nas escolas e discute o papel do professor nessa perspectiva.

Os módulos do curso foram assim definidos:

- Módulo 1: Contexto, princípios e propósitos da Educação Integral, com 50 horas

- Módulo 2: A educação Integral e a atuação do professor, com 50 horas

A concepção pedagógica inovadora do curso de formação de professores tem como base a abordagem Construcionista, Contextualizada e Significativa (CCS) (Schlünzen \& Santos, 2016; Schlünzen, Schlünzen Junior \& Santos, 2017), por meio da qual o estudante é levado a construir projetos pedagógicos de seu interesse, que façam parte do seu contexto e tenham significado. Assim, permite-se aflorar o interesse do professor-estudante, motivandoo a explorar, a pesquisar, a descrever, a refletir, a depurar suas ideias, com a mediação pedagógica, de maneira a desenvolver, por meio do uso das Tecnologias Digitais de Informação e Comunicação (TDIC), um projeto que faz parte da sua vivência e da escola onde trabalha, em um processo reflexivo dentro da sua própria realidade.

Em um contexto no qual os atores e a comunidade ensinam e aprendem por meio da abordagem CCS, seja na formação ini- 
cial e continuada de professores, seja no contexto da escola, seja em contextos polissêmicos formativos, as TDIC podem ser usadas como recursos facilitadores para a construção do conhecimento dos estudantes, possibilitando que encontrem a sua autoimagem, podendo atuar como seres pensantes em nossa sociedade. Neste processo, as TIDIC podem ser usadas para que o estudante possa produzir algo, como por exemplo: um aplicativo, uma história ilustrada, um desenho, um texto, um cartaz, entre outros, ou simplesmente comunicar-se ou buscar informações.

Dessa forma, à medida que o estudante vê seu interesse individual ser transformado num contexto social e/ou científico, verá suas habilidades afloradas e o processo de ensino será enriquecido.

Portanto, os pressupostos da abordagem CCS podem ser descritos como:

a) os estudantes podem ter potencialidades e habilidades exploradas, desde que sejam encontradas formas que possibilitem a expressão, a produção e a comunicação;

b) as TDIC podem ser usadas para construir o conhecimento de acordo com as possibilidades individuais e coletiva, oferecendo uma base segura para repensar a aprendizagem e o ensino em condições e ambientes diferentes;

c) o acesso a diferentes recursos tecnológicos, favorecendo a vivência em várias situações associadas a um contexto e a um significado fazem o processo de ensinar e aprender ser mais motivador;

d) a aprendizagem por meio do desenvolvimento de projetos oferece possibilidades de reflexão e de produção das mais diversas maneiras, integrando as disciplinas e possibilitando muitas formas de expressão. 
Desenvolver propostas na abordagem CCS usando as TDIC pode abrir grandes possibilidades para que os estudantes consigam progredir significativamente em pelo menos um dos aspectos de suas necessidades: na aprendizagem (cognitiva, social, política, afetiva ou emocional), no uso da tecnologia (inclusão digital) e, para muitos, mais do que isso, no trabalho que permite a compreensão do que está se aprendendo. Dessa forma, contribuindo para que a vida dos estudantes no aspecto de socialização e afetividade, além do cognitivo, seja melhorada.

Essas iniciativas de consolidação da abordagem CCS permitem identificar, mesmo timidamente, uma tendência de reorientação das escolas, segundo uma nova lógica educacional regida por princípios sociais, democráticos, de justiça, de igualdade, contrapondo-se à tendência que é sustentada por valores econômicos e empresariais de produtividade, competitividade, eficiência, modelos ideais, que tantas exclusões têm provocado na educação, em todos os seus níveis (Mantoan, 2002).

Portanto, o projeto pedagógico para o desenvolvimento de competências socioemocionais nas escolas é um produto decorrente do curso de formação com base na abordagem CCS, que dialoga com a concepção de Educação Integral, de forma que tenham uma experiência educativa. Além disso, o advento da BNCC no Brasil, reforçando o compromisso nacional com a Educação Integral e o desenvolvimento pleno, reforça a urgência de propostas inovadoras para a formação docente.

Os autores que defendem uma epistemologia complexa, como Edgar Morin, representam a base teórica para dialogar com o conceito de Educação Integral. Além das reflexões epistemológicas, as publicações da OCDE, OMS e de autores e instituições que desenvolvem pesquisas e projetos com competências socioemocionais compõem o referencial teórico que ampara os conceitos discutidos e que substanciam a formação de professores que é proposta neste projeto. 
Uma Educação Integral sugere metodologias e processos avaliativos compatíveis com seus princípios. Numa educação que visa o pleno desenvolvimento humano, avaliar significa mais do que medir o que o estudante aprendeu ao final de um percurso de aprendizagem. A avaliação deve se dar em processos coletivos e interativos que se traduzam em indicadores dos ajustes necessários e ações efetivas que compõem o percurso de aprendizagem.

Nesse sentido, o curso propõe um diálogo importante com experiências contextualizadas e significativas e práticas de forma a impactar a transposição didática para o desenvolvimento pleno dos estudantes, promovendo uma articulação curricular entre as áreas de conhecimento, instituindo metodologias comuns entre as áreas que dialogam com a concepção de Educação Integral. Tais metodologias são fortemente destacadas no curso de maneira que os cursistas tenham uma experiência educativa de educação integral.

\section{Os Resultados com o Projeto}

No Brasil, ao trabalharmos na esfera pública, encontramos o desafio da descontinuidade de propostas educativas nas mudanças de governo, pois equipes de liderança são substituídas gerando instabilidade nos programas e a necessidade de formação de novas equipes demandando um constante esforço nesse sentido. Outro desafio é a precariedade de recursos de algumas escolas, dificuldade de acesso à internet, escassez de computadores, livros e materiais didáticos que dificultam o trabalho de professores e a aprendizagem dos estudantes.

A avaliação experimental do projeto, conduzida entre 2014 e 2016, demonstrou que há um grande efeito, em termos de aprendizado, para os alunos que frequentaram as escolas envolvidas. Em Matemática, o aumento médio observado no desempenho dos alunos causado pela escola e medido a partir das avaliações externas da rede escolar, foi de 1,1 desvios-padrão. Para ilustrar a 
magnitude do efeito, considere que, no Brasil, em 2015, dos alunos que fizeram o Pisa, apenas $30 \%$ tiveram um desempenho acima do considerado adequado pela OCDE. Se o aumento médio observado em três anos fosse aplicado a todos os alunos que fizeram o Pisa, esse percentual subiria para $70 \%$. Ou seja, supondo que fosse possível que todos os alunos tivessem o mesmo aumento de desempenho experimentado, em média, pelos alunos que frequentaram as escolas envolvidas com o projeto, o percentual de alunos com desempenho adequado em matemática mais que dobraria.

A cada novo território em que o projeto é implementado ele recebe adaptações de forma a se ajustar com o currículo. Na parceria com UNESP, o percurso formativo foi construído de forma que os cursistas revisitassem suas práticas tanto à luz da BNCC implementadas no Brasil, como do currículo da cidade recém implementado e do contexto escolar onde trabalha como professor.

Em termos quantitativos, nos últimos dois anos implementamos o projeto nos seguintes estados brasileiros:

\section{7}

- Rio de Janeiro: projeto formou 197 professores e 136 gestores em curso online, e 125 gestores/ multiplicadores em um formato presencial com impacto em 655 professores.

- Santa Catarina: o projeto formou 207 professores de 15 escolas, e 54 gestores no modelo presencial.

\section{8}

- Rio de Janeiro: o projeto formou 250 gestores/ multiplicadores no modelo presencial, o que significa um potencial de alcance de 1.300 professores, beneficiando diretamente 7.000 jovens.

- Santa Catarina: o projeto formou aproximadamente 361 professores e 91 gestores no modelo presencial.

- São Paulo: a versão online do curso formou aproximadamente 200 professores e estudantes de licenciatura que atuam na região metropolitana de 
São Paulo, beneficiando indiretamente mais de 10.000 estudantes.

$\mathrm{Na}$ avaliação realizada pelos professores e estudantes, o formato híbrido do curso favoreceu a interação entre os cursistas, tutores e coordenação, gerando maior troca de experiências, reflexão e construção de conhecimentos e ampliação do repertório teórico e prático sobre Educação Integral e contribuições para a atuação profissional.

Além disso, toda interação está registrada no Ambiente Virtual de Aprendizagem (AVA), possibilitando uma boa análise sobre a construção e reflexão diária dos envolvidos no curso, bem como, as atividades que realizaram em seus respectivos contextos escolares.

Os tutores atuaram de forma comprometida e competente na mediação pedagógica e na gestão de cada turma favorecendo a boa interação, reflexão, aprendizagem colaborativa na construção de conhecimentos e ampliação de exemplos sobre os princípios e metodologias de Educação Integral.

Finalmente, quanto aos objetivos alcançados podemos indicar os seguintes:

- a construção de conhecimentos sobre os princípios e propósitos da Educação integral no Brasil.

- a Educação Integral articulada ao desenvolvimento de competências cognitivas e socioemocionais.

- a construção de conhecimentos sobre o currículo na Educação Integral - olhares sobre a criança e o jovem que queremos formar.

- o contato com metodologias de Educação Integral que influenciaram as práticas docentes (planejamento integrado, atuação colaborativa, gestão da aula e avaliação formativa).

- a observação das políticas e das tendências de Educação Integral, nacionais e internacionais para o século 21 . 


\section{Cenários e Tendências para o Futuro}

Precisamos urgentemente entender que as tecnologias provocam mudanças na concepção de novas metodologias para a Educação, favorecendo a construção de ambientes de aprendizagem que exploram o potencial das tecnologias na direção de ambientes ricos, contextualizados, personalizados, acessíveis e significativos e que podem servir de suporte para o desenvolvimento de atividades educacionais compartilhadas e orientadas por professores para o desenvolvimento de competências socioemocionais. Acreditar no potencial formador de uma educação híbrida é desenvolver uma nova perspectiva de educação centrada no humano, mas que dá à educação uma nova perspectiva da mesma forma como ocorre em demais setores da sociedade, principalmente em um mundo no qual teremos que aprender continuamente, sem a dependência física para encontrar materiais, diferentes fontes de informação e conhecimento, e para interagir em uma estrutura de redes de aprendizagem.

$\mathrm{Na}$ educação superior significa aliar competências em ensino, pesquisa e extensão na construção de uma academia que terá sua capacidade expandida, incluindo o acesso ao seu conhecimento e, a uma formação mais integral, democrática e inclusiva.

É inegável que os principais avanços científicos que vivenciamos nas últimas décadas tem relação estreita com o desenvolvimento das tecnologias digitais. Acabamos dependendo quase que integralmente do uso de equipamentos digitais para nosso trabalho, para nossas pesquisas, para nossa vida em sociedade, em nossos cuidados com a saúde, etc.

Por outro lado, muito pouco é feito de forma efetiva para o emprego das tecnologias em contextos educacionais, no fomento de ambientes educacionais cuja finalidade primordial é fazer com que as pessoas aprendam e que, por meio desse aprendizado, possam aplicar os conhecimentos construídos na vida profissional e cotidiana. 
É fato que vivemos hoje um cenário no qual as tecnologias digitais ampliam nossas habilidades cognitivas e sensoriais, ao ponto de não conseguirmos viver sem elas. Partindo dessa constatação, se elas potencializam sobremaneira nossas capacidades, por que não empregá-las em ambientes de aprendizagem? Limitarmos o processo educacional à figura única do professor que professa o que sabe, é perpetuar uma realidade que teria algum sentido em um tempo muito distante. Além disso, entender que o estudante é um ser integralmente dependente do professor, do espaço físico acadêmico, é relegar a educação a um processo de dependência, de não autonomia, nada criativo e muito hierarquizado, características que não interessam ao futuro profissional em formação.

Portanto, uma educação que deve continuar tendo o professor como o orquestrador do processo, mas aliado ao uso das tecnologias digitais, em um estar junto virtual (Valente, 2002), pode nos conduzir a uma educação on line que combina toda a competência docente com as potencialidades do digital. Este cenário parece ideal para ir ao encontro de um mundo mais globalizado e conectado, e sintetiza o que pode ser observado no mundo.

Todavia, quando falamos em garantir o direito à educação em um país como o Brasil, o cenário muda radicalmente. Segundo a Pesquisa Nacional por Amostra de Domicílios (PNAD), realizada pelo Instituto Brasileiro de Geografia e Estatística em 2015 (IBGE, 2016) que pesquisou 356.904 pessoas entre 2014 e 2015, o número de brasileiros com 25 anos ou mais com diploma do ensino superior era de apenas $13,5 \%$, resultado muito inferior quando comparado a outros países com economias muito mais modestas. Além disso, nessa mesma faixa etária, temos $11,1 \%$ da população com menos de um ano de estudo, 31,3\% com ensino fundamental incompleto ( $9,6 \%$ completaram), 4,1\% com ensino médio incompleto $(26,4 \%$ completaram) e, $3,8 \%$ com ensino superior incompleto. (IBGE, 2016).

Considerando nossas aspirações e comprometimento com uma sociedade melhor, acreditamos que a tecnologia pode promover o empoderamento das pessoas no sentido de acesso igualitário ao 
conhecimento, promovendo sua integração na comunidade e no mundo do trabalho. Isso só será possível com o uso intenso das tecnologias como recurso de inclusão social e escolar.

A recente resolução publicada pelo Ministério da Educação do Brasil (MEC) que flexibiliza as ações de EaD e de uso das tecnologias no ensino superior é um indicador de que há muito a ser feito. O objetivo do Decreto 9.057/2017, segundo as informações do MEC, é "ampliar a oferta de ensino superior no país para atingir a Meta 12 do Plano Nacional de Educação (PNE), que exige elevar a taxa bruta de matrícula na educação superior para $50 \%$ e a taxa líquida em 33\% da população de 18 e 24 anos." (Ministério da Educação, 2017). Nesse sentido, a flexibilização teria o intuito principal de estimular as Instituições de Ensino Superior a aumentarem a oferta de cursos, possibilitando uma maior concorrência e, um maior acesso aos cursos oferecidos a distância.

É preciso entender, entretanto, que trata-se de uma regulamentação que flexibiliza um pouco mais as iniciativas, mas que não tira das Universidades a responsabilidade pela qualidade de educação ser oferecida, quer seja presencial, a distância ou híbrida. Nesta direção, não conhecemos melhor período da história da humanidade para dispormos de tantos recursos, quer sejam tecnológicos de interação, construção de conhecimento e de conectividade do que temos hoje. No entanto, tudo isso não basta. É necessário utilizálos para conectar competências acadêmicas aos estudantes, com qualidade e acessibilidade aos materiais didático-pedagógicos, com metodologias que transformem os estudantes em construtores do seu próprio conhecimento, tarefas que não podem ser meramente entendidas por meio de Leis. É necessário um processo de diálogo acadêmico e de institucionalização das tecnologias na rotina acadêmica, de construção de novos ambientes de aprendizagem que não se resumem em colocar um verniz de tecnologia nos superados espaços com carteiras dispostas cartesianamente.

No Brasil, menos de um terço dos alunos brasileiros tem um desempenho adequado na escola, e apenas 10\% têm desempenho adequado em Matemática. Esses índices ficam ainda piores quan- 
do analisamos as regiões com menor índice de desenvolvimento humano.

Nesse contexto educacional desolador, as dificuldades enfrentadas pelos professores da rede pública brasileira são enormes. Uma carreira extremamente desvalorizada: apenas 2\% dos estudantes do Ensino Médio querem se tornar professores. Nos cursos de Pedagogia, quase não há conexão entre a formação inicial e a prática. E, depois de formados, são poucas as oportunidades de crescimento na profissão. O resultado é inevitável: muitos desistem e deixam a sala de aula.

Assim, é necessária uma revisão, por meio de uma proposta formativa como a descrita neste artigo, que agregue as competências socioemocionais, a fim de formar estudantes preparados para os desafios do Século 21. Essa proposta, que nasceu da união entre a expertise do Instituto Ayrton Senna na Educação Integral, com a experiência acadêmica e formativa da Unesp, possibilitou a concretização de um curso híbrido de formação de professores para disseminar a concepção de Educação Integral para estudantes e profissionais de educação, dentro de uma diversidade de contextos que estão presentes em uma das maiores metrópoles do planeta.

\section{Referencias bibliográficas}

Adams Becker, S., Brown, M., Dahlstrom, E., Davis, S., Depaul, K., Diaz, V. e Pomerantz, J. (2018). NMC Horizon Report: 2018 Higher Education Edition. Louisville, CO: EDUCAUSE. Disponível em https://library. educause.edu/ /media/files/library/2018/8/2018horizonreport.pdf

Barros, D. M. V. (Novembro 2018). Estilos de Uso do Virtual: Estratégias de Personalização da Aprendizagem. Apresentação em IV Congresso Nacional de Formação de Professores e XIV Congresso Estadual Paulista de Formação de Formadores, Universidade Estadual Paulista UNESP em Águas de Lindóia, São Paulo, Brasil. 
Durlak, J. A., Weissberg, R. P., Dymnicki, A. B., Taylor, R. D. e Scheillinger, K. B. (2011). The Impact of Enhancing Student's Social and Emotional Learning: A Meta-Analysis of School-Based Universal Interventions. Child Development Journal, 82(1), 405-432.

EDUCAUSE. (2019). Horizon Report Preview, 2019 Higher Education Edition. Louisville, CO: EDUCAUSE. Disponível em https://library. educause.edu/-/media/files/library/2019/2/2019horizonreportpreview. pdf

Huertas, E., Biscan, E., Ejsing, C., Kerber, L., Kozlowska, L., Ortega, S. M., Lauri, L., Risse, M., Schorg, K. e Seppmann, G. (2018). Considerations for quality assurance of e-learning provision. Buxelles: European Association for Quality Assurance in Higher Education-ENQA. Disponível em http:// enqa.eu/index.php/publications/papers-reports/occasional-papers/.

IBGE-Instituto Brasileiro de Geografia e Estatística. (2016). Pesquisa Nacional por Amostra de Domicílios: síntese de indicadores: 2015. Rio de Janeiro: IBGE, Coordenação de Trabalho e Rendimento. Disponível em https://biblioteca.ibge.gov.br/visualizacao/livros/liv98887.pdf

Mantoan, M. T. E. (2002). Ensinando a turma toda: as diferenças na escola. Pátio: Revista Pedagógica, (20), 8-28.

Ministério da Educação. (2017). Atualizada legislação que regulamenta Educação a Distância no país. Brasília: Ministério da Educação Ministério da Educação. Disponível em http://portal.mec.gov.br/component/ content/article?id=49321.

Ministério da Educação. (2018). Base Nacional Comum Curricular (BNCC). Brasília: Ministério da Educação Ministério da Educação. Disponível em http://basenacionalcomum.mec.gov.br/

Quintana, J. (2019). Resumen comparativo de los Informes Horizon de 2010 a 2019: ¿la crónica de un despropósito? Recuperado de https://drive.google.com/file/d/OB-UH40RuxWIEcEYzNXBBdzliUzQ/ view? usp=sharing 
Santos, D. A. N. e Schlünzen, E. T. M. (2007). Use of Information and Communication Technologies (ICT) and work with projects in the formation of teachers in service at the state public school system. In A. J. Mendes, I, Pereira e R. Costa (Org.), Computers and education towards educational change and innovation (pp. 261-270). Londres: Springer.

Schlünzen, E. T. M. e Santos, D. A. N. (2016). Práticas Pedagógicas do Professor: abordagem construcionista, contextualizada e significativa para uma educação inclusiva. Curitiba, PR: Appris.

Schlünzen, E. T. M., Schlünzen Junior, K. e Santos, D. A. N. (2017). Enfoque construccionista, contextualizado y significativo: entornos educativos inclusivos en la era digital. In J. Quintana e Ó. Y. Aparicio (Eds.), Temas emergentes en Educación (pp. 69-86). Colombia: Ediciones Universidad Central.

Sklad, M., Dieskstra, R., De Ritter, M. E. e Ben, J. (2012). Effectiveness of School-Based Universal Social, Emotional, and Behavioral Programs: Do they enhance students' development in the area of skill, behavior and adjustment? Psychology in the Schools, 49(9), 892-909.

Valente, J.A. (2002). A espiral da aprendizagem e as tecnologias da informação e comunicação: repensando conceitos. In M. C. Joly (Ed.), Tecnologia no ensino: implicações para a aprendizagem (pp.15-37). São Paulo: Casa do Psicólogo. 